\title{
Variations in the management of acute exacerbations of chronic obstructive pulmonary disease
}

\author{
Supna K Sandhu MD, Jackson Chu BSc, Marko Yurkovich BSc, David Harriman MD, \\ Catalin Taraboanta MD MSc, J Mark FitzGerald MD
}

SK Sandhu, J Chu, M Yurkovich, D Harriman, C Taraboanta, JM FitzGerald. Variations in the management of acute exacerbations of chronic obstructive pulmonary disease. Can Respir J 2013;20(3): 175-179.

BACKGROUND: Acute exacerbations of chronic obstructive pulmonary disease (AECOPD) are a significant cause of morbidity and mortality for patients with COPD. AECOPD are the leading cause of hospital admissions in Canada. Although multiple guidelines have been developed for the acute and chronic management of COPD, there are few quality assurance studies investigating adherence to these guidelines.

METHODS: A retrospective chart review of all patients admitted to a tertiary care hospital in 2009 for an AECOPD was performed. Using a standardized data abstraction tool, adherence to current guidelines across different physician groups and patient outcomes were assessed. Particular focus was centred on differences in management across physician groups. RESULTS: Overall, 293 patients were evaluated. Of these, $82.6 \%$ were treated with one or more chronic COPD medication(s) in the community, with only $17.7 \%$ of patients treated with a long-acting inhaled anticholinergic medication. For treatment of AECOPD, $58 \%$ of patients received corticosteroids and $84 \%$ received antibiotics. Compared with general medicine and the hospitalist service, the respiratory medicine service demonstrated significantly better adherence with current treatment guidelines; however, even this was less than optimal. In addition, there was poor follow-up of patients cared for outside of the respiratory service.

CONCLUSIONS: The present study identified significant care gaps in the treatment of patients admitted with AECOPD and on their discharge.

Key Words: Chronic obstructive lung disease; Health outcomes; Variations in practice

$A$ cute exacerbations of chronic obstructive pulmonary disease (AECOPD), also known as 'lung attacks', are the fourth leading cause of death globally and are the leading cause of hospital admissions in Canada. Following admission for an AECOPD, there is a significant relapse rate, with up to $18 \%$ of patients being readmitted within one year $(1,2)$. In Canada, the overall direct economic burden of this disease has been estimated to be $\$ 1.5$ billion per year (3). Given this significant burden, the Global initiative for chronic Obstructive Lung Disease (GOLD) and the Canadian Thoracic Society's COPD guidelines have been developed for the management of COPD $(2,4)$. These guidelines emphasize the importance of a thorough history and physical examination as well as, in more severe exacerbations, chest $\mathrm{x}$-rays, arterial blood gas (ABG) measurements and additional laboratory investigations to assess the severity of AECOPD. The use of antibiotics, oral corticosteroids and bronchodilators as treatment cornerstones have also been emphasized (4). More recently, we have recommended better risk stratification of patients with lung attacks, with a view to improving subsequent management at the time of discharge (5). For moderate to severe chronic COPD, there is strong evidence supporting the use of 'triple therapy' (6). This triple therapy, which consists of a long-acting beta agonist (LABA) combined with an inhaled corticosteroid (ICD) and a long-acting anticholinergic, has been shown to reduce the risk of hospitalization from AECOPD (6).

\section{Les variations dans la prise en charge des exacerbations aiguës de la maladie pulmonaire obstructive chronique}

\begin{abstract}
HISTORIQUE : Les exacerbations aiguës de la maladie pulmonaire obstructive chronique (EAMPOC) sont d'importantes causes de morbidité et de mortalité chez les patients ayant une MPOC. Les EAMPOC sont la principale cause d'hospitalisations au Canada. Même s'il existe de multiples lignes directrices sur la prise en charge aiguë et chronique de la MPOC, peu d'études sur l'assurance de la qualité traitent du respect de ces lignes directrices.

MÉTHODOLOGIE : Les chercheurs ont procédé à une analyse rétrospective de tous les patients hospitalisés dans un hôpital de soins tertiaires à cause d'une EAMPOC en 2009. Au moyen d'un outil standardisé d'abstraction des données, ils ont évalué le respect des lignes directrices à jour entre les divers groupes de médecins et les issues des patients. Ils se sont attardés sur les différences de prise en charge entre groupes de médecins.
\end{abstract}

RÉSULTATS : Dans l'ensemble, 293 patients ont été évalués. De ce nombre, $82,6 \%$ étaient traités au moyen d'au moins un médicament contre la MPOC dans la collectivité, tandis que seulement $17,7 \%$ recevaient des anticholinergiques par aérosol à action prolongée. Pour traiter leur EAMPOC, $58 \%$ des patients ont reçu des corticoïdes et $84 \%$, des antibiotiques. Par rapport au service de médecine générale et hospitaliste, le service de pneumologie respectait beaucoup mieux les lignes directrices à jour sur les traitements, mais laissait tout de même à désirer. De plus, le suivi des patients soignés à l'extérieur du service de pneumologie était médiocre.

CONCLUSIONS : La présente étude a permis de déterminer d'importantes lacunes dans le traitement des patients hospitalisés en raison d'une EAMPOC et à leur congé.

Quality assurance studies for the management of COPD have revealed suboptimal compliance with current clinical guidelines $(7,8)$. A prospective study by Rowe et al (7) found that corticosteroids and antibiotics were used in $65 \%$ and $46 \%$ of patients, respectively, presenting to Canadian emergency departments with an AECOPD. For inpatient management, Lindenauer et al (8) found a 97\% compliance rate for bronchodilators and an $85 \%$ compliance rate for systemic steroids and antibiotics for patients admitted with AECOPD.

The purpose of the present study was to assess the management of COPD at the time of admission and discharge; to determine adherence to current guidelines by respiratory physicians, emergency department (ED) physicians, internists and hospitalists; and to determine the outcomes of patients presenting with AECOPD.

\section{METHODS}

All patients admitted to Vancouver General Hospital (VGH, Vancouver, British Columbia) with a diagnosis of AECOPD were identified. A retrospective chart and computer information system review was conducted. Patients seen in the ED in 2009 with a selfreported previous diagnosis of COPD and a primary discharge diagnosis of AECOPD were included in the present study. For patients with multiple visits, only the first ED visit was included. Additional hospital visits were documented as relapses if they occurred within three or

Departments of Medicine and Emergency Medicine, and the Institute for Heart and Lung Health, University of British Columbia, Vancouver, British Columbia

Correspondence: Dr Supna K Sandhu, Departments of Medicine and Emergency Medicine, Institute for Heart and Lung Health, University of British Columbia, The Lung Centre, 7th Floor, Gordon and Leslie Diamond Health Care Centre, 2775 Laurel Street, Vancouver,

British Columbia V5Z 1M9. Telephone 604-875-4122, fax 604-875-4695, e-mail supna.s@gmail.com 


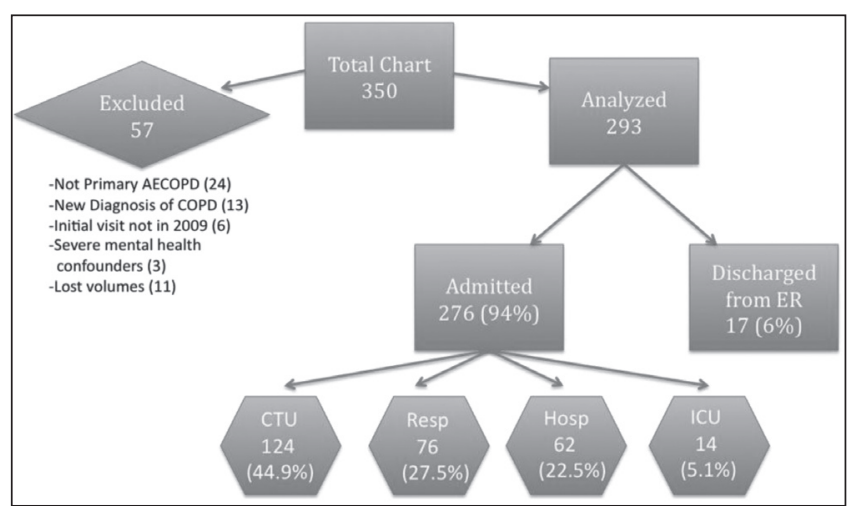

Figure 1) Disposition of patients with acute exacerbation of chronic obstructive pulmonary disease (AECOPD) in 2009. CTU Clincal teaching unit; ER Emergency room; Hosp Hospitalist service; ICU Intensive care unit; Resp Respiratory medicine service

28 days of the original index visit, or under total visits in 2009. Patients were excluded if they did not have a pre-existing diagnosis of COPD or if they had a severe, pre-existing mental health issue. Patients were also excluded if AECOPD was a secondary discharge diagnosis and not primarily responsible for their hospital stay.

Three investigators (SS, MY and JC) were trained to abstract data both from the medical charts and the hospital's computer system. A standardized data abstraction form was developed. To ensure interrater agreement, a kappa statistic was computed. Abstracted data included the following: the Canadian Triage and Acuity Scale score; Pharmanet (a province-wide universal data base providing an electronic list of prescribed medications for each patient); COPD-related medication prescribed in the ED and during admission and at discharge; use of preprinted orders; relapse rates; salbutamol at discharge; documented follow-up; patient smoking habits, forced expiratory volume in $1 \mathrm{~s}\left(\mathrm{FEV}_{1}\right)$ measurements; and ABG values. One of the reviewers (SS) was a study investigator and was not blinded to the study hypothesis; however, the other two investigators were blinded.

The following information was recorded for all patients: demographic information (age, sex); mode of arrival to the ED (emergency health services or self); presence of comorbidities (heart disease, metabolic disease, skeletal disease, other diseases); smoking history (current, total pack years); COPD medications (bronchodilators, ICDs, combination therapy, antibiotics, oral corticosteroids, home oxygen); previous physicians involved in patient care (family physicians, respirologists); time of arrival to ED; Canadian Triage and Acuity Scale score; time to see ED physician; total time in ED; presence of Pharmanet printout; diagnostic evaluations (chest $\mathrm{x}$-ray, $\mathrm{ABG}$ ); involvement of a respiratory therapist; use of preprinted orders; resource intensity weights, which measure the health care resources used during hospital stay; treatment modalities (bronchodilators, ICDs, combination therapy, antibiotics, systemic corticosteroids, bilevel positive airway pressure, furosemide, intubation); disposition (admitted, discharged from ED); discharge suitability and plans; development or presence of comorbidities; and in-hospital mortality rates.

The present study was conducted with approval from the University of British Columbia Human Ethics Committee (Vancouver, British Columbia).

\section{Statistical analysis}

All statistical analyses were performed using SPSS version 12.0 (IBM Corporation, USA). Categorical values were reported as counts and percentages with 95\% CIs. Continuous variables were reported as means and SDs, or as medians with interquartile range, as appropriate. For comparison among three or more groups, ANOVA and $\chi^{2}$ tests were used to determine statistical significance, which was set at $\mathrm{P}<0.05$.
TABLE 1

Baseline characteristics of patients

\begin{tabular}{lc}
\hline Age, years, mean $\pm \mathrm{SD}(\mathrm{n}=293)$ & $74.2 \pm 11.4$ \\
Sex & \\
Male & $155 / 293(52.9)$ \\
Female & $138 / 293(47.1)$ \\
Mode of arrival & \\
Self & $95 / 278(34.2)$ \\
Emergency health service & $180 / 278(64.8)$ \\
Previous family physician & $276 / 289(95.5)$ \\
Previous respirologist & \\
Previously intubated & $12 / 285(4.1)$ \\
Current smoker & $76 / 218(34.9)$ \\
Comorbidities & \\
0 & $75 / 293(25.6)$ \\
1 & $97 / 293(33.1)$ \\
2 & $82 / 293(28.0)$ \\
$\geq 3$ & $39 / 293(13.3)$ \\
Congestive heart failure & $48 / 293(21.8)$ \\
Depression & $22 / 293(10.0)$ \\
Osteoporosis & $27 / 293(12.3)$ \\
Hypertension & $123 / 293(55.9)$ \\
Diabetes mellitus & $52 / 293(23.6)$ \\
Obstructive sleep apnea & $4 / 293(1.8)$ \\
Lung cancer & $21 / 293(9.5)$ \\
Chronic kidney disease & $5 / 293(1.7)$ \\
Duration of symptoms, $\mathrm{h}$ & \\
$<24$ & $89 / 290(30.7)$ \\
$24-72$ & $28 / 290(16.6)$ \\
$>72$ & $145 / 290(50.0)$ \\
\hline Da present & \\
\hline & \\
\hline & \\
\hline
\end{tabular}

Data presented as $n / n$ (\%) unless otherwise indicated

\section{RESULTS}

The kappa values among the different data abstractors for the study variables ranged from 0.85 to 0.99 .

\section{Patient demographics and disposition (Figure 1)}

A total of 350 charts were analyzed, of which 57 were excluded for reasons ranging from the subject not having a primary discharge diagnosis of AECOPD to lost chart volumes. After exclusion, a total of 293 patients remained. Seven patients were admitted directly to the ward, while the remaining 286 came through the ED. The group had a mean age of 74.2 years and $52.9 \%$ were male.

\section{Patient characteristics (Table 1)}

The majority (95.5\%) of subjects had a named family physician; however, only $15.4 \%$ had been documented as having been seen by a respiratory physician. Seventy-four per cent of patients $h a d \geq 1$ pre-existing comorbidities, of which systemic hypertension (55.9\%), diabetes mellitus $(23.6 \%)$ and congestive heart failure $(21.8 \%)$ were the most prevalent. Most patients (64.8\%) were brought to the ED by emergency health services and $50 \%$ experienced worsening symptoms for at least $72 \mathrm{~h}$ before presentation.

\section{COPD medications on arrival to the ED (Table 2)}

In total, $82.6 \%$ of patients were treated with $\geq 1$ maintenance COPD medications in the community. Fifty-eight per cent were treated with salbumatol, $40 \%$ with ipratropium, $47.1 \%$ with a combination of an ICD and a LABA, and $17.7 \%$ with tiotropium. A minority of AECOPD patients were concurrently being treated with prednisone (13.7\%) and antibiotics (18.6\%). 
Disposition from the ED (Figure 1)

The vast majority $(94.1 \%)$ of patients were admitted to hospital, while the ED physician directly discharged $5.9 \%$ of patients from the ED. One of the admitted patients exhibited aggressive behaviour and was escorted out of the ED by security; therefore, 275 patients remained for analysis of their care following admission. Among admitted patients, $5.1 \%$ went directly to the intensive care unit, $44.9 \%$ to the clinical teaching unit (CTU) of general medicine, $27.5 \%$ to respiratory medicine and $22.5 \%$ to the hospitalist service.

\section{Analysis of admitted patients (Tables 3 and 4)}

Patients admitted to the respiratory medicine service were significantly younger (mean $[ \pm$ SD] age $69.5 \pm 11$ years) than those admitted to the CTU or under the care of a hospitalist. Resource intensity weights were not statistically different among the three groups. More ABG measurements were performed in patients admitted to the respirology service $(68.4 \%$ versus $48.4 \%$ for general internists, and $21.0 \%$ for hospitalists; $\mathrm{P}<0.0001)$ whereas chest $\mathrm{x}$-rays were nearly universal (96\% to $98 \%)$. On admission, patients seen by the respiratory medicine service had more acidotic ABGs $(\mathrm{pH} 7.35 \pm 0.09$ versus $\mathrm{pH} 7.38 \pm 0.08$ for general internists, and $\mathrm{pH} 7.4 \pm 0.05$ for hospitalists; $\mathrm{P}=0.015)$ and more carbon dioxide retention $(59.7 \pm 25.1 \mathrm{mmHg}$ versus $49.1 \pm 17.3 \mathrm{mmHg}$ for general internists and $46.7 \pm 12.3 \mathrm{mmHg}$ for hospitalists; $\mathrm{P}=0.014)$, despite similar supplemental oxygen levels (fraction of inspired oxygen $[\mathrm{P}=0.866]$ ) compared with the other services. The majority of patients were treated with an antibiotic (79\% to $88 \%)$. Significantly more patients admitted to the respiratory service were treated with corticosteroids $(78.9 \%$ versus $53.2 \%$ for general internists and $27.4 \%$ for hospitalists) and given deep vein thrombosis prophylaxis (60.5\% versus $34.7 \%$ for general internists, and $46.8 \%$ for hospitalists). Patients admitted to the respiratory service were also significantly more likely to have their management directed by the use of preprinted orders. Additional findings included an almost total absence of the use of spirometry testing among patients not cared for by the respiratory service.

Outcomes and management on discharge (Table 5)

A minority of patients were discharged on 'triple therapy', with the respiratory medicine service prescribing this therapy to significantly more patients $(47.1 \%)$ than general internists and hospitalists.
TABLE 2

Management of patients before arrival to the emergency department

\begin{tabular}{lc}
\hline Chronic COPD medications & $242 / 293(82.6)$ \\
Salbutamol & $171 / 293(58.4)$ \\
Ipratropium & $117 / 293(40.0)$ \\
Fluticasone/salmeterol & $118 / 293(40.3)$ \\
Budesonide/formoterol & $20 / 293(6.8)$ \\
Tiotropium & $52 / 293(17.7)$ \\
AECOPD medications & \\
Prednisone & $40 / 293(13.7)$ \\
Antibiotics & $53 / 285(18.6)$ \\
\hline
\end{tabular}

Data presented as $n / n$ (\%). AECOPD Acute exacerbation of chronic obstructive pulmonary disease; COPD Chronic obstructive pulmonary disease

General internist's patients had the shortest length of stay (LOS) in hospital, with a median LOS of four days (range three to seven days). Relapse rates ( $8.9 \%$ to $14 \%)$ and rates of death $(7.9 \%$ to $10.5 \%)$ did not statistically differ among the three physician groups.

Outcomes of all patients (Table 6)

Thirty-two per cent of patients in the present cohort with the primary discharge diagnosis of AECOPD had $\geq 2$ visits to the VGH ED in 2009, with $52.6 \%$ of these patients experiencing their second exacerbation within 28 days. In other words, $16.7 \%$ of all COPD patients experienced at least one relapse to the VGH ED within 28 days. For the patients who relapsed, the median number of ED visits in 2009 was 3.8 per person and the median number of admissions in 2009 was 2.8 per person.

\section{DISCUSSION}

In the present study, we identified multiple opportunities for improvement in patient care. Patients requiring an admission to hospital for an AECOPD are those with moderate to severe COPD and should, therefore, based on results of multiple randomized controlled trials, be eligible for 'triple therapy' (6). Although spirometry data were not available for this patient population, by virtue of hospital admission for AECOPD, this population would qualify for 'triple therapy' (6). We found that only $17.7 \%$ of patients were treated with a long-acting

\section{TABLE 3}

\section{Characteristics of admitted patients}

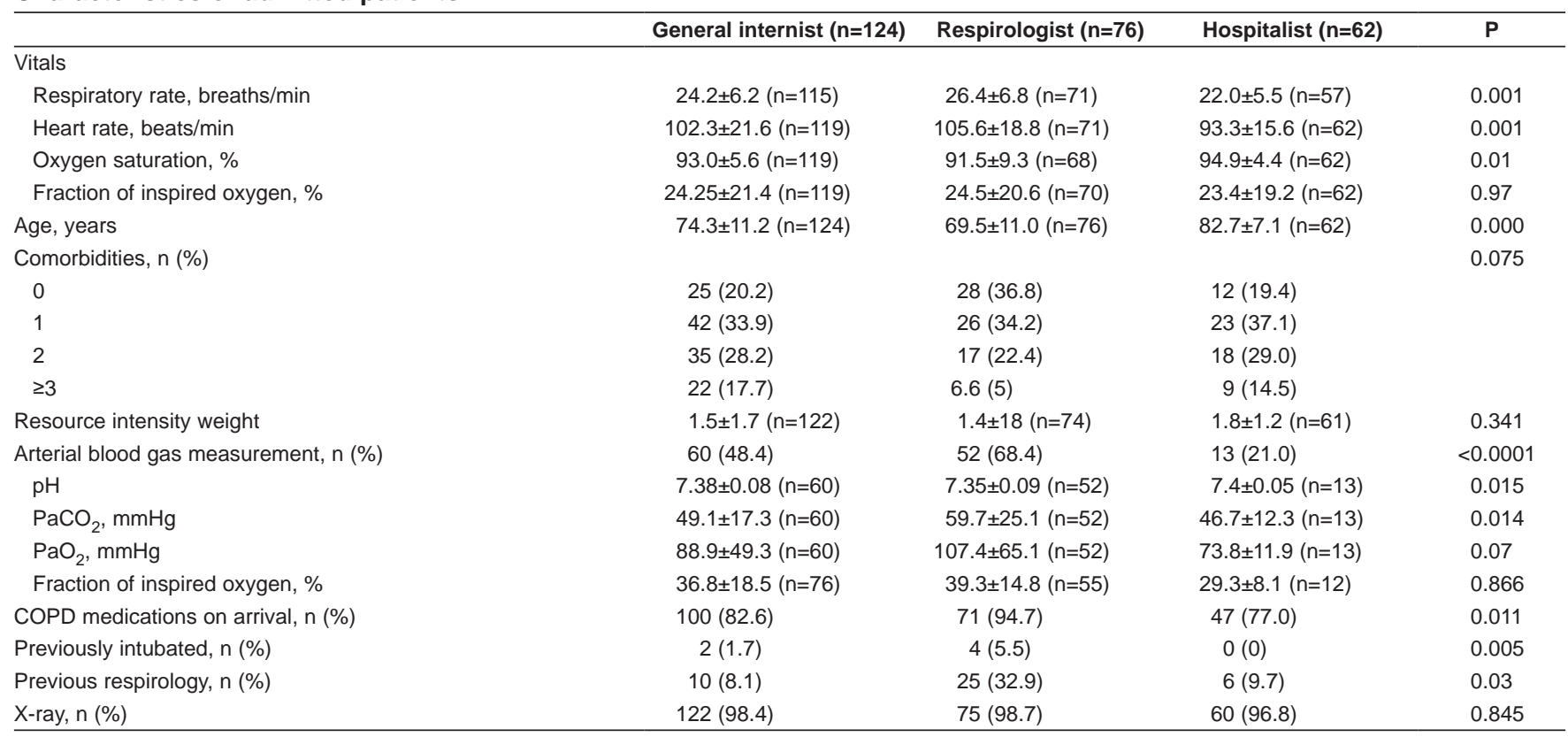

Data presented as mean \pm SD unless otherwise indicated. COPD Chronic obstructive pulmonary disease; $\mathrm{PaCO}_{2}$ Partial pressure of carbon dioxide; $\mathrm{PaO}{ }_{2}$ Partial pressure of oxygen 
TABLE 4

Chronic obstructive pulmonary disease management on admission

\begin{tabular}{lcccc}
\hline & $\begin{array}{c}\text { General } \\
\text { internist } \\
(\mathbf{n}=\mathbf{1 2 4})\end{array}$ & $\begin{array}{c}\text { Respirologist } \\
(\mathbf{n}=\mathbf{7 6})\end{array}$ & $\begin{array}{c}\text { Hospitalist } \\
(\mathbf{n}=62)\end{array}$ & $\mathbf{P}$ \\
\hline Preprinted orders & $6(4.8)$ & $44(57.9)$ & $0(0)$ & $<0.0001$ \\
Salbutamol & $96(77.4)$ & $74(97.4)$ & $50(80.6)$ & 0.001 \\
Ipratropium & $99(79.8)$ & $71(93.4)$ & $39(62.9)$ & $<0.0001$ \\
Heparin & $43(34.7)$ & $46(60.5)$ & $29(46.8)$ & 0.003 \\
Prednisone & $66(53.2)$ & $60(78.9)$ & $17(27.4)$ & $<0.0001$ \\
Antibiotics & $102(82.3)$ & $67(88.2)$ & $49(79)$ & 0.345 \\
Spirometry & $8(6.5)$ & $40(52.6)$ & $2(3.2)$ & $<0.0001$ \\
\hline
\end{tabular}

Data presented as $n$ (\%) unless otherwise indicated

\section{TABLE 5}

Outcomes and management at discharge of admitted patients

\begin{tabular}{lcccc}
\hline & $\begin{array}{c}\text { General } \\
\text { internist } \\
(\mathbf{n}=\mathbf{1 2 4})\end{array}$ & $\begin{array}{c}\text { Respirologist } \\
(\mathbf{n}=\mathbf{7 6})\end{array}$ & $\begin{array}{c}\text { Hospitalist } \\
(\mathbf{n}=62)\end{array}$ & $\mathbf{P}$ \\
\hline Management at discharge & & & & \\
$\quad$ Salbutamol & $52(49.1)$ & $42(60.0)$ & $27(48.2)$ & 0.213 \\
Ipratropium bromide & $48(45.3)$ & $24(34.3)$ & $24(42.9)$ & 0.41 \\
Tiotropium & $17(15.5)$ & $37(52.9)$ & $13(23.2)$ & $<0.0001$ \\
ICS + LABA & $46(43.4)$ & $50(71.4)$ & $28(50.0)$ & $<0.0001$ \\
Home oxygen & $11(10.0)$ & $22(31.4)$ & $6(10.7)$ & $<0.0001$ \\
Length of stay, days, & $4(3-7)$ & $6.5(5-9.75)$ & $7(6-11)$ & $<0.0001$ \\
$\quad$ median (IQR) & & & & \\
Deceased & $13(10.5)$ & $6(7.9)$ & $6(9.7)$ & 0.823 \\
Relapse rate to VGH & $12(11.0)$ & $10(14.3)$ & $5(8.9)$ & 0.640 \\
\hline
\end{tabular}

Data presented as $n$ (\%) unless otherwise indicated. IQR Interquartile range; LABA Long-acting beta agonist (LABA) + inhaled corticosteroid (ICS) Advair (GlaxoSmithKline Inc, Canada), Symbicort (AstraZeneca Inc, Canada) or combination budesonide, or Flovent (GlaxoSmithKline Inc, Canada) and Serevent (GlaxoSmithKline Inc, Canada); VGH Vancouver General Hospital, Vancouver, British Columbia

anticholinergic and only $25.6 \%$ of patients were discharged on this 'triple therapy'. Given the significant economic burden of COPD to our health care system, patients should undergo a review of their medications and have treatment optimized at the time of discharge to reduce the risk of relapse and to prevent accelerated loss of lung function and future exacerbations on hospital discharge (4). Without this optimization of therapy, relapse rates and health care costs will continue to climb.

In the present study, $94 \%$ of patients presenting to the ED with an AECOPD were admitted. This admission rate is strikingly higher than the rate reported in previous studies, in which $67 \%$ of patients were admitted (7). This is consistent with previous analyses that have shown more hospital-based treatment in Canada for AECOPD compared with outpatient-based treatment in the United States (7).

Whereas adherence with chest $\mathrm{x}$-rays was nearly universal in the present study, only one-half of the patients underwent ABG testing, which is consistent with rates reported in previous studies (8). Whereas Canadian Thoracic Society COPD guidelines do not recommend the routine use of ABG measurements to risk stratify patients and monitor recovery if patients are on room air with appropriate oxygen saturations, current GOLD guidelines are less definitive $(2,4)$. Furthermore, we found a scarcity in the use of spirometry testing throughout a patient's stay. Although the GOLD guidelines recommend against the routine use of spirometry in the setting of AECOPD, it may be useful to document a patient's $\mathrm{FEV}_{1}$ before discharge to optimize COPD medications (4).
TABLE 6

Outcomes for all acute exacerbations of chronic obstructive pulmonary disease patients at one tertiary care hospital in 2009

\begin{tabular}{lc}
\hline Admission for relapses, $\mathrm{n} / \mathrm{n}(\%)$ & $28 / 246(10.1)$ \\
0 to 3 days & $4 / 28(14)$ \\
$\geq 3$ to 28 days & $24 / 28(86)$ \\
Emergency room visits, mean $(\mathrm{n} / \mathrm{n})$ & \\
All patients & $1.7(245 / 245)$ \\
Relapsed patients & $3.8(41 / 245)$ \\
Admissions, mean $(\mathrm{n} / \mathrm{n})$ & \\
All patients & $1.4(245 / 245)$ \\
Relapsed patients & $2.8(41 / 245)$ \\
\hline
\end{tabular}

Despite the existence of preprinted orders to highlight optimal treatment of patients with AECOPD, these orders were used infrequently. For the entire cohort, $42 \%$ of patients did not receive systemic corticosteroids and $16 \%$ did not receive antibiotics. Regarding the failure to use antibiotics, our results were similar to previous studies that reported compliance rates in the 80th percentile (9-11). Our data regarding the use of corticosteroids is also similar to a recent COPD audit that found a $15 \%$ to $40 \%$ failure rate for the use of corticosteroids during AECOPD (8). One Danish study that examined reasons behind this lack of compliance revealed a lack of physician awareness of guidelines to be a major contributing factor (12). Overall, only $51.8 \%$ of patients received ideal care with a bronchodilator, systemic corticosteroids and systemic antibiotics.

Relapse rates and LOS were higher among our patient population than previously reported $(9,13)$. The primary likely reason for this was the suboptimal treatment of patients in our study population. There may also be additional factors including differences in health care practice between the public health care system in Canada and the private system in the United States. These high relapse rates significantly contribute to the economic burden that COPD places on the health care system. Previous studies have shown that patients are at the greatest risk of relapse within the first eight weeks of discharge; this further highlights the importance of appropriate discharge medications and follow-up on discharge to prevent these relapses (7).

An interesting finding was the relatively short LOS for patients admitted to the CTU. This finding may, in part, relate to the fact that general internal medicine teams are on call every five nights and, from a logistical point of view, need to discharge patients before the next wave of admitted patients arrive at their hospital units. This practice may contribute to the shorter LOS for these patients cared for by internists but may also be a contributing factor to the high rate of readmission in this patient population. Our total sample size was not large enough to confirm this hypothesis.

Significant care gaps were also identified among general internists, respiratory physicians and hospitalists. Respiratory physicians were more likely to adhere to current guidelines for the use of corticosteroids, deep vein thrombosis prophylaxis and nebulizers; however, even these rates were not optimal. Although it is true that patients admitted under the general medicine and hospitalist services tended to have less severe AECOPD according to ABG values, Canadian Thoracic Society and GOLD guidelines recommend corticosteroids for all patients experiencing AECOPD, regardless of disease severity. Interestingly, although patients admitted to the respiratory service were somewhat sicker, the mortality rate in that cohort was lower than the other two groups of patients. Respiratory physicians also placed a significantly higher proportion of patients on appropriate 'triple therapy' on discharge. To our knowledge, the present study was the first to compare in-patient management of AECOPD among general internists, respiratory physicians and hospitalists. Given the proven efficacy of triple therapy in reducing the risk of AECOPD, it would appear that 
there is significant potential for improvement in the care of COPD patients on being discharged into the community. We recently strongly argued that patients admitted to hospital with an AECOPD should be better managed with risk stratification and appropriate optimization of maintenance therapy at the time of discharge (5).

The present study highlights the importance of continuing education for specialists, hospitalists and family physicians to enable optimal patient care. It is not surprising that respirologists adhere better to COPD guidelines because they are the experts in their field. Venous thromboembolisms (VTE), for instance, were recently found to cause or complicate up to $25 \%$ of cases of AECOPD with previously unknown etiology compared with $8 \%$ of cases with a known etiology (14). Given this potential for VTE to contribute to AECOPD, inpatients admitted for an AECOPD should be placed on VTE prophylaxis. The variations in management found among the groups in the present study illustrate the importance of the creation and implementation of evidence-based, preprinted orders for patient management.

The present study had several limitations. Because it was a retrospective chart review, data collection was limited to information transcribed by health care professionals in patient charts. Furthermore, only relapses to one hospital were recorded; therefore, it is possible that this may be an under-representation because several other hospitals are in close proximity.

\section{REFERENCES}

1. Benady S. The Human and Economic Burden of COPD: A Leading Cause of Hospital Admission in Canada. Report by the Canadian Thoracic Society, 2010. <www.lung.ca/cts-sct/pdf/COPDReport_E. pdf $>$ (Accessed November 2011).

2. O'Donnell DE, Hernandez P, Kaplan A, et al. Canadian Thoracic Society recommendations for management of chronic obstructive pulmonary disease - 2008 update - highlights for primary care. Can Respir J 2008:15(Suppl A).

3. Mittmann N, Kuramoto L, Seung SJ, et al. The cost of moderate and severe COPD exacerbations to the Canadian healthcare system. Respir Med 2008;102:413-21.

4. GOLD Executive Committee. Global initiative for chronic Obstructive Pulmonary Disease: Pocket guide to COPD diagnosis, management, and prevention. Updated 2008. <www.goldcopd.org/ Guidelines/guidelines-resources.html>. (Accessed June 2011).

5. FitzGerald JM. Targeting lung attacks. Thorax 2011;66:365-6.

6. Aaron SD, Vandemheen KL, Fergusson D, et al; for the Canadian Thoracic Society/Canadian Respiratory Clinical Research Consortium. Tiotropium in combination with placebo, salmeterol, or fluticasone/salmeterol for chronic obstructive pulmonary disease: A randomized trial. Ann Intern Med 2007;146:545-55.

7. Rowe BH, Cydulka RK, Tsai CL, Clark S, Sinclair D, Camargo CA Jr. Comparison of Canadian versus United States emergency department visits for chronic obstructive pulmonary disease exacerbation. Can Respir J 2008;15:295-301.

8. Lodewijckx C, Sermeus W, Vanhaecht K, et al. Inhospital management of COPD exacerbations: A systematic review of the

\section{CONCLUSIONS}

The present study identified significant care gaps in the management of patients with AECOPD and stable COPD. Among different physician groups, respirologists comply with current guidelines significantly more than general internists and hospitalists; however, compliance was still not optimal. It is imperative that guidelines be followed given the large burden of COPD on our health care system. One potential way in which to improve care is through the implementation of preprinted orders for the treatment of AECOPD.

ACKNOWLEDGEMENT: The authors thank Dr Don Sin for his thoughtful comments on reviewing the manuscript.

AUTHOR CONTRIBUTIONS: SS: study design, ethics approval, data collection, statistical analysis and manuscript production; MY: data collection; JC: data collection; DH: study design and ethics approval; CT: statistical analysis and manuscript revision; MF: study design, ethics approval, statistical analysis and manuscript revision.

DICLOSURES: The authors have no financial disclosures or conflicts of interest to declare.

literature with regard to adherence to international guidelines. J Eval Clin Pract 2009;15:1101-10.

9. Lindenauer PK, Pekow P, Gao S, Crawford AS, Gutierrez B, Benjamin E. Quality of care for patients hospitalized for acute exacerbations of chronic obstructive pulmonary disease. Ann Intern Med 2006;144:894-903.

10. Bratzler DW, Oehlert WH, McAdams LM, Leon J, Jiang H, Piatt D. Management of acute exacerbations of chronic obstructive pulmonary disease in the elderly: Physician practices in the community hospital setting. J Okla State Med Assoc 2004;97:227-32.

11. Gibson PG, Wlodarczyk JH, Wilson AJ, Sprogis A. Severe exacerbation of chronic obstructive airways disease: Health resource use in general practice and hospital. J Qual Clin Pract 1998;18:125-33.

12. Phanareth K, Hansen LS, Christensen LK, Laursen LC, Hansen EF. Treatment of acute severe asthma and chronic obstructive pulmonary disease in Danish hospitals. Do national recommendations improve on the quality of the treatment? Respir Med 2002;96:653-58.

13. Hurst JR, Donaldson GC, Quint JK, Goldring JJP, Baghai-Ravary F, Wedzicha JA. Temporal clustering of exacerbations in chronic obstructive pulmonary disease. Am J Respir Crit Care Med 2009;179:369-74.

14. Gunen G, Gulbas G, In E, Yetkin O, Hacievliyagil SS. Venous thromboemboli and exacerbations of COPD. Eur Respir J 2010;35:1243-8. 


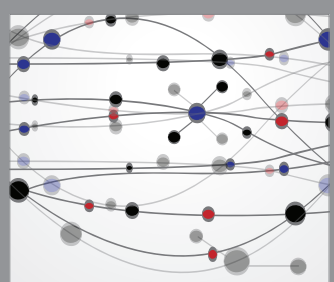

The Scientific World Journal
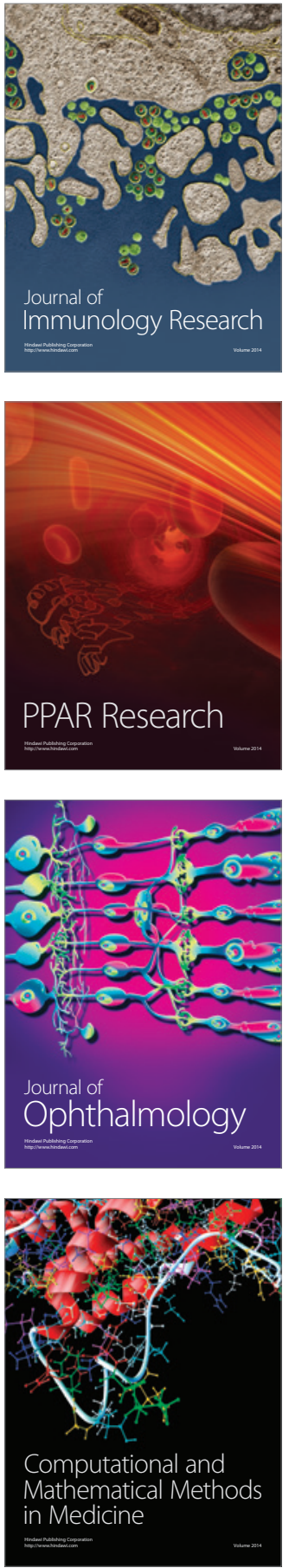

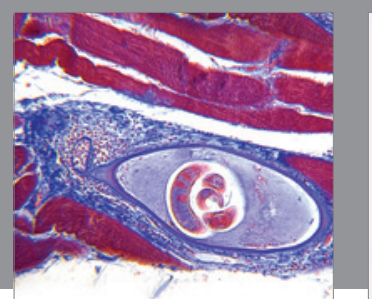

Gastroenterology Research and Practice

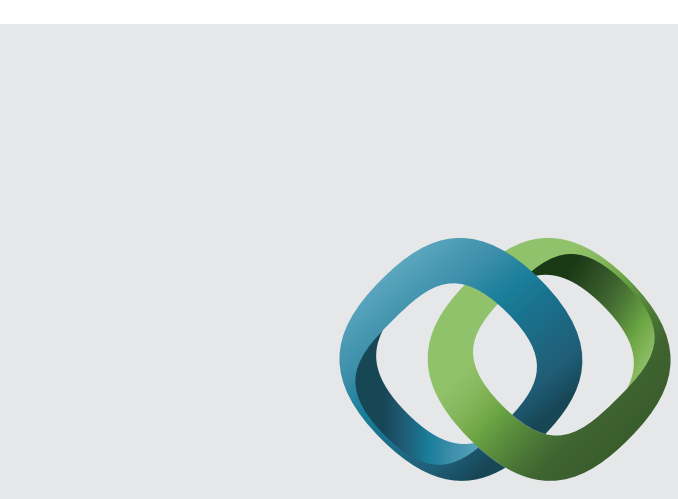

\section{Hindawi}

Submit your manuscripts at

http://www.hindawi.com
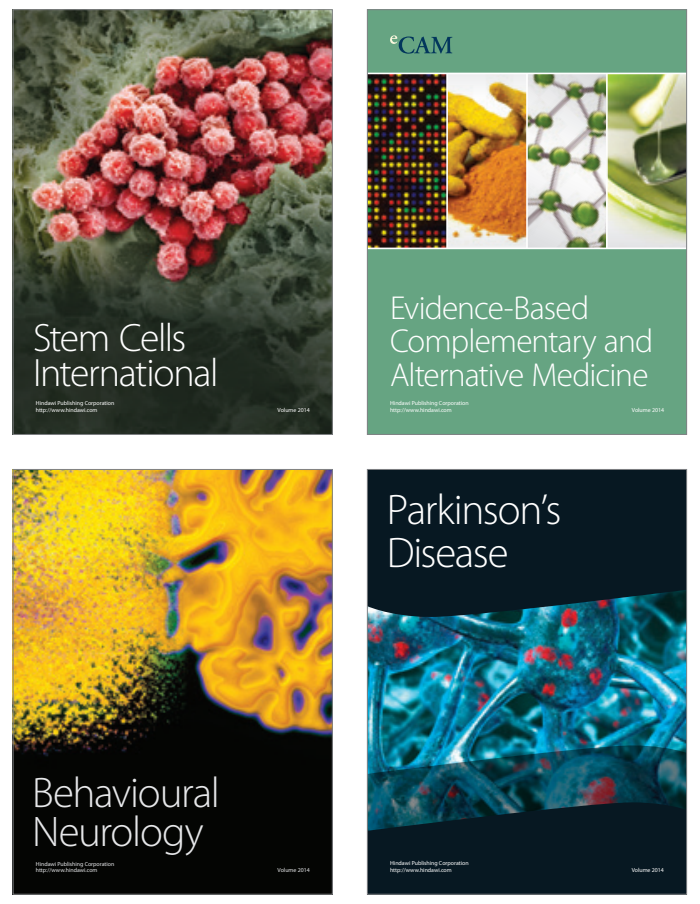
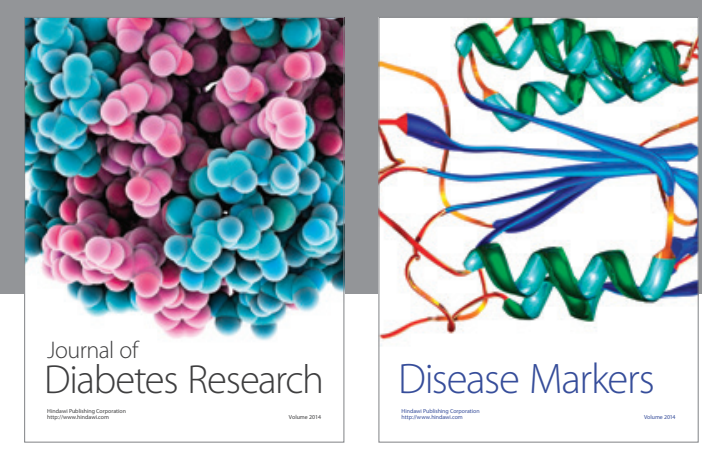

Disease Markers
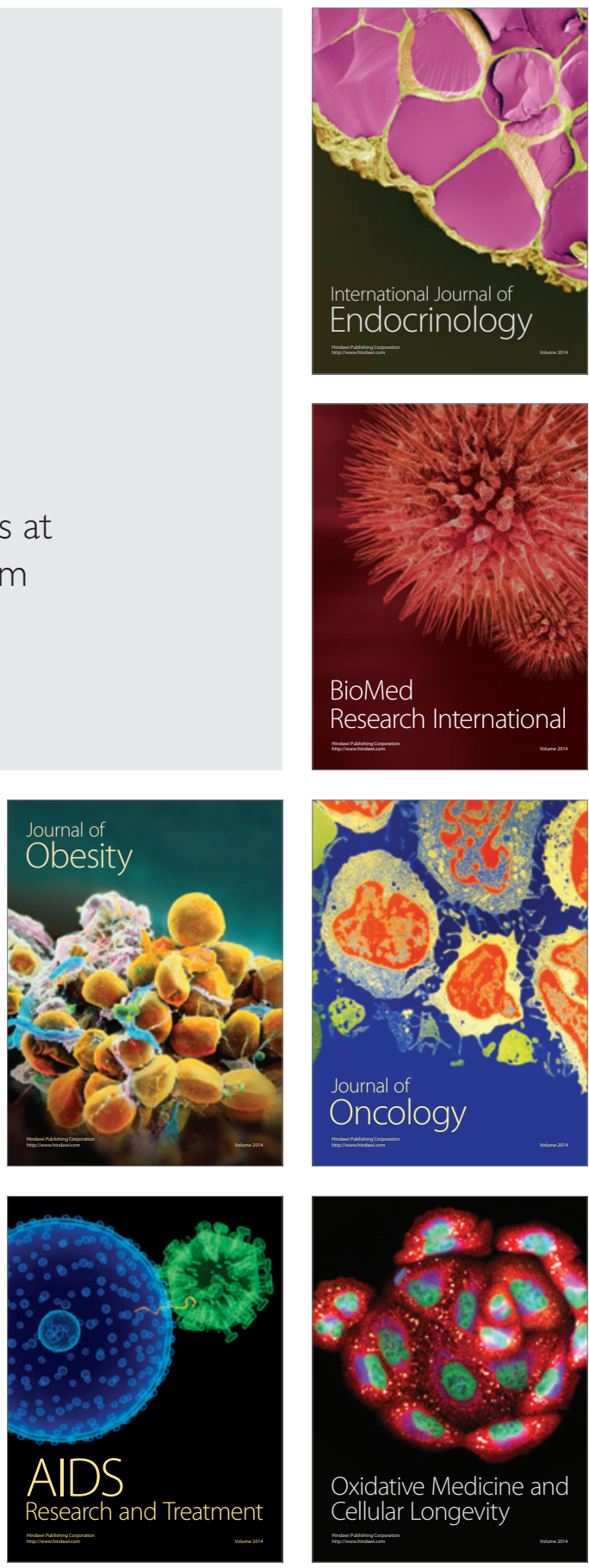